\title{
EFEKTIFITAS PERAWATAN TERHADAP PROSES PENYEMBUHAN TALI PUSAT PADA BAYI BARU LAHIR DI RSUD LABUANG BAJI MAKASSAR
}

\author{
Sitti Nurul Hikma Saleh \\ Program Studi DIII-Kebidanan, STIKES Graha Medika \\ Jln. Raya AKD. RSI Moonow, Lantai II, Kelurahan Mongkonai Barat Kota Kotamobagu, \\ nurulhikmasaleh93@gmail.com
}

Diterima 2 Januari 2020, disetujui 24 Maret 2020, diterbitkan 30 April 2020

Pengutipan: Saleh, S. N. H. (2020). Efektifitas Perawatan Terhadap Proses Penyembuhan Tali Pusat pada Bayi Baru Lahir di RSUD Labuang Baji Makasar Tahun 2016.Gema Wiralodra, Vol 11, No 1, Hal 26-34, April 2020

\begin{abstract}
ABSTRAK
Perawatan adalah proses perbuatan, cara merawat, pemeliharaan, penyelenggaraan. Hal yang paling terpenting dalam membersihkan tali pusat adalah memastikan tali pusat dan area di sekelilingnya selalu bersih dan kering. Selalu mencuci tangan dengan menggunakan air bersih dan sabun sebelum membersihkan tali pusat. Selama tali pusat belum puput, sebaiknya bayi tidak dimandikan dengan cara dicelupkan ke dalam air. Cukup diusap saja dengan kain yang direndam air hangat. Penelitian ini bertujuan untuk mengetahui efektifitas perawatan terhadap proses penyembuhan tali pusat pada bayi baru lahir di RSUD Labuang Baji 2016. Rancangan penelitian menggunakan metode analitik dengan pendekatan Cros sectional Study untuk melihat hubungan antara perawatan tehnik terbuka, dan perawatan tehnik tertutup dengan penyembuhan luka tali pusat. Jumlah sampel yang digunakan sebanyak 31 orang yang merupakan bayi baru lahir di RSUD Labuang Baji Makassar. Hasil dari penelitian menunjukkan bahwa terdapat hubungan antara perawatan tehnik terbuka, dan perawatan tehnik tertutup dengan penyembuhan luka tali pusat dengan nilai masing-masing: perawatan tehnik terbuka ( $\rho$ value $=0,235)$, dan perawatan tehnik tertutup $(\rho$ value $=0,235)$. Kesimpulan pada penelitian ini yaitu ada hubungan perawatan tehnik terbuka dan perawatan tehnik tertutup terhadap penyembuhan luka tali pusat.
\end{abstract}

Kata Kunci: Perawatan Tali Pusat, Penyembuhan Tali Pusat, Bayi Baru Lahir

\begin{abstract}
Care is the process of doing, how to care for, maintain, administer. The most important thing in cleaning the umbilical cord is to make sure the umbilical cord and the area around it are always clean and dry. Always wash your hands with clean water and soap before cleaning the umbilical cord. As long as the umbilical cord is not broken, the baby should not be bathed by dipping it in water. Just wipe it with a cloth soaked in warm water. This study aims to determine the effectiveness of treatment of the umbilical cord healing process in newborns in Labuang Baji Hospital in 2016. The study design uses analytical methods with Cros sectional Study approach to see the relationship between open technique treatment, and closed technique treatment with umbilical cord wound healing. The number of samples used as many as 31 people who are newborns in Labuang Baji Hospital Makassar.The results of the study indicate that there is a relationship between open technique treatments, and closed technique treatments with umbilical cord healing with their respective values: open technique treatments ( $\rho$ value $=0.235$ ), and closed technique treatments ( $\rho$ value $=0.235$ ). The conclusion of this study is that there is a relationship between open technique treatment and closed technique treatment for umbilical cord wound healing.
\end{abstract}

Keywords: Umbilical Cord Care, Umbilical Cord Healing, Newborns

Diterbitkan oleh:

Universitas Wiralodra

Jln. Ir. H. Juanda Km 3 Indramayu, Jawa Barat 


\section{PENDAHULUAN}

Persalinan adalah proses dimana seorang ibu melahirkan bayinya. Pada saat bayi baru lahir terjadi proses adaptasi dengan dunia luar yang jauh berbeda dengan keadaan dalam rahim sehingga terjadi perubahan (Jumiarni, 2001). Akibat perubahan lingkungan dari uterus ke luar uterus, maka bayi baru lahir menerima rangsangan yang bersifat kimiawi, mekanis dan termis. Hasil rangsangan ini membuat bayi akan mengalami perubahan metabolisme, pernafasan, sirkulasi dan lain-lain (Wiknjosastro, 2002). Di samping itu bayi dituntut melakukan metabolisme dan melaksanakan segala sistem tubuhnya sendiri seperti bernafas, mencerna, eliminasi dan lain-lain yang semula tergantung pada ibunya.

Periode lain adalah terjadinya infeksi terutama pada tali pusat yang merupakan luka basah dan dapat menjadi pintu masuknya kuman tetanus yang sangat sering menjadi penyebab kematian bayi baru lahir (Jumiarni, 2002). Sebelum terjadi penutupan anatomik yang sempurna pembuluh darah tali pusat merupakan tempat masuknya kuman yang paling baik,sehingga bayi mudah menderita infeksi (Markum, 2002). Untuk itu perlu dilakukan perawatan tali pusat.

Perawatan tali pusat dengan tehnik tertutup yaitu membersihkan tali pusat dengan menggunakan alkohol atau membungkus tali pusat dengan alkohol. Mungkin sebagian orang tua baru merasa takut melihat tali pusat yang belum terlepas. Tali pusat boleh ditutup atau diikat dengan longgar pada bagian atas tali pusat dengan menggunakan kassa steril. Pastikan tali pusat tidak tertekan oleh pakaian ataupun tali kain popok bayi (Riksani, 2012). Perawatan tali pusat dengan tehnik terbuka yaitu WHO merekomendasikan, untuk perawatan sehari-hari tali pusat cukup dengan membersihkan tali pusat dengan air dan sabun kemudian dibiarkan terlebih dahulu di udara terbuka hingga benar-benar kering.

Sampai saat ini di rumah sakit banyak yang menggunakan tehnik perawatan tertutup yaitu membersihkan tali pusat dengan alkohol $70 \%$, luka tali pusat dikompres kassa alkohol $70 \%$ kemudian ditutup dengan kassa steril (Cristine, 2002). Dan mulai tahun 2002, sejak adanya pelatihan APN mulai dikembangkan tehnik perawatan terbuka dengan membersihkan tali pusat sampai kering kemudian pertahankan sisa tali pusat dalam

Diterbitkan oleh: 
keadaan terbuka agar terkena udara dan tutup dengan sehelai kassa steril (PPKC, 2002). Perawatan tali pusat yang kurangan baik dan salah dapat mempengaruhi lamanya proses pengeringan dan lamanya waktu lepas serta dapat menyebabkan infeksi sehingga hal ini tidak efektif terhadap penyembuhan tali pusat (Cuningham, 2002). Tanda lain yang perlu diwaspadai pada tali pusat akibat perawatan yang kurang baik adalah adanya tanda kemerahan, bengkak, keluar cairan, bau busuk dan berdarah (PPKC, 2002).

Walaupun belum ditemukan kejadian infeksi tali pusat selama dirawat di rumah sakit, sampai saat ini dilaporkan rata-rata penyembuhan luka tali pusat terjadi beberapa hari setelah perawatan di rumah dengan rentang waktu yang bervariatif. Rata-rata tenaga keperawatan yang bertugas di PNC belum mengetahui tingkat efektifitas dari kedua perawatan yang dilakukan pada tali pusat bayi baru lahir. Dan sampai saat ini belum ada penelitian tentang perawatan ini. Menurut, Cunningham (2002) menyatakan tali pusat mengering lebih cepat dan lepas lebih awal apabila perawatannya dilakukan dengan tehnik terbuka, dan karena itu pembalutan tak dianjurkan. Manfaat lain dari perawatan terbuka tentu akan lebih sedikit bahan dan alat habis pakai yang akan digunakan bidan yang bertugas, sehingga akan menekan biaya yang dikeluarkan rumah sakit. Sedangkan perawatan tali pusat tehnik tertutup didasarkan pada kajian literatur yang menyatakan bahwa dengan tehnik tertutup akan mencegah terjadinya kontaminasi dengan dunia luar dan melindungi luka tali pusat dari gesekan, walaupun secara ekonomi akan lebih banyak bahan dan alat yang diperlukan.

Berdasarkan data yang diperoleh dari rekam medik di RSUD Labuang Baji Makassar pada Tahun 2014 terdapat perawatan tali pusat terbuka sebanyak 57 bayi $(81,42 \%)$ dan perawatan tali pusat tertutup sebanyak 13 bayi $(18,57 \%)$ dari 70 bayi baru lahir, sedangkan pada tahun 2015 terdapat 67 bayi (89,33\%) dengan perawatan tali pusat terbuka dan 8 bayi $(10,66 \%)$ dengan perawatan tali pusat tertutup dari 75 bayi baru lahir. Tujuan penelitian ini yaitu mengetahui efektifitas perawatan terhadap proses penyembuhan tali pusat pada bayi baru lahir di RSUD Labuang Baji Makassar tahun 2016.

Diterbitkan oleh: 


\section{METODE PENELITIAN}

Jenis penelitian ini yang digunakan adalah metode Analitik dengan pendekatan Cross Sectional Study. Populasi dalam penelitian adalah semua bayi baru lahir di RSUD Labuang Baji Makassar pada saat penelitian sedangkan sampel adalah sebagian dari populasi. Besar sampel dalam penelitian sebanyak 31 responden. Pengambilan sampel menggunakan teknik Purposive Sampling. Pengumpulan data diperoleh dari data primer dengan menggunakan kuesioner dan data sekunder yang didapatkan dari data rekam medik di RSUD Labuang Baji Makassar pada tahun 2016. Analisis data menggunakan uji Chi Square.

\section{HASIL DAN PEMBAHASAN}

\section{Hasil Penelitian}

Penelitian dilakukan terhadap 31 sampel bayi baru lahir. Adapun yang diteliti terdiri dari variabel dependen yaitu penyembuhan luka tali pusat dan variabel independen terdiri dari perawatan tehnik terbuka dan perawatan tehnik tertutup. Berdasarkan hasil analisis univariat pada Tabel 1 pada variabel perawatan tehnik terbuka menunjukkan bahwa responden yang mengalami penyembuhan luka tali pusat lebih banyak yang melakukan perawatan tehnik terbuka yaitu sebanyak 15 orang $(88,2 \%)$ dibanding yang tidak melakukan perawatan tehnik terbuka yaitu 10 orang $(71,4 \%)$. Sedangkan responden yang tidak mengalami penyembuhan luka tali pusat lebih banyak yang tidak melakukan perawatan tahnik terbuka yaitu sebanyak 4 orang $(28,6 \%)$ dibanding yang hipertensi yaitu 2 orang $(11,8 \%)$.

Pada variabel perawatan tehnik tertutup lebih menunjukkan bahwa responden yang mengalami penyembuhan luka tali pusat lebih banyak yang tidak menggunakan perawatan tehnik tertutup yaitu sebanyak 15 orang $(88,2 \%)$ dibanding yang menggunakan tehnik tertutup yaitu 10 orang $(71,4 \%)$. Sedangkan responden yang tidak mengalami penyembuhan luka tali pusat lebih banyak pada responden yang menggunakan perawatan tehnik tertutup yaitu sebanyak 4 orang $(28,6 \%)$ dibanding yang tidak menggunakan perawatan tehnik tertutup yaitu 2 orang $(11,8 \%)$.

Diterbitkan oleh: 
Tabel 1. Analisis Bivariat

\begin{tabular}{|c|c|c|c|c|c|c|}
\hline \multirow{3}{*}{ Variabel Independen } & \multicolumn{4}{|c|}{ Penyembuhan Luka Tali Pusat } & \multirow{3}{*}{$\begin{array}{c}\text { Total } \\
\mathrm{N}\end{array}$} & \multirow{3}{*}{$P$ value } \\
\hline & \multicolumn{2}{|c|}{$\mathrm{Ya}$} & \multicolumn{2}{|c|}{ Tidak } & & \\
\hline & $\mathrm{n}$ & $\%$ & $\mathrm{~N}$ & $\%$ & & \\
\hline $\begin{array}{l}\text { Perawatan Tehnik } \\
\text { Terbuka }\end{array}$ & & & & & & \\
\hline $\mathrm{Ya}$ & 15 & 88,2 & 2 & 11,8 & 17 & \\
\hline Tidak & 10 & 71,4 & 4 & 28,6 & 14 & 0,235 \\
\hline Jumlah & 25 & 80,6 & 6 & 19,4 & 31 & \\
\hline $\begin{array}{l}\text { Perawatan Tehnik } \\
\text { Tertutup }\end{array}$ & & & & & & \\
\hline $\mathrm{Ya}$ & 10 & 71,4 & 4 & 28,6 & 14 & \\
\hline Tidak & 15 & 88,2 & 2 & 11,8 & 17 & 0,235 \\
\hline Jumlah & 25 & 80,6 & 6 & 19,4 & 31 & \\
\hline
\end{tabular}

Berdasarkan hasil uji Chi Square diperoleh nilai $\rho=0,235$ atau $(\rho<0,05)$. Maka Ho pada penelitian ini ditolak artinya, bahwa ada hubungan antara perawatan tehnik terbuka dengan penyembuhan luka tali pusat. Sedangkan variabel perawatan tehnik tertutup diperoleh nilai $\rho=0,235$ atau $(\rho<0,05)$. Maka Ho pada penelitian ini ditolak artinya, bahwa ada hubungan antara perawatan tehnik tertutup dengan penyembuhan luka tali pusat.

\section{Pembahasan}

Perawatan adalah proses perbuatan, cara merawat, pemeliharaan, penyelenggaraan (Kamisa, 2002). Hal yang paling terpenting dalam membersihkan tali pusat adalah memastikan tali pusat dan area di sekelilingnya selalu bersih dan kering. Selalu mencuci tangan dengan menggunakan air bersih dan sabun sebelum membersihkan tali pusat. Selama tali pusat belum puput, sebaiknya bayi tidak dimandikan dengan cara dicelupkan ke dalam air. Cukup diusap saja dengan kain yang direndam air hangat (Sinsin, 2008).

Hasil penelitian efektifitas perawatan tehnik terbuka terhadap proses penyembuhan tali pusat pada bayi baru lahir di RSUD Labuang Baji Makassar tahun 2016., memperlihatkan $\rho$ value $0,235<0,05$ hal ini menunjukkan bahwa terdapat hubungan antara perawatan tehnik terbuka dengan penyembuhan luka tali pusat.

Diterbitkan oleh: 
Perawatan tehnik terbuka adalah dengan membiarkan tali pusat terbuka setelah dilakukan perawatan. Pertimbangan tehnik terbuka ini adalah akan lebih cepat proses penyembuhan jika luka tali pusat ditinggalkan terpapar dengan udara luar dari pada jika ditutup dengan kassa pembalut cenderung untuk menimbulkan kelembaban pada luka (Sacharin, 2004)

Persiapan yang harus disiapkan pada perawatan tehnik terbuka adalah :1). Perlengkapan memandikan bayi, 2). Perlengkapan pakaian bayi (gurita, popok, baju) 3). Sehelai kassa steril, 4). Bengkok. Pelaksanaan pada perawatan tehnik terbuka, setelah bayi selesai dimandikan dan kulit dikeringkan maka perawatan tali pusat sebagai berikut ; 1). Keringkan tali pusat mulai dari ujung sampai pangkal tali pusat dan daerah sekitarnya dengan diameter $2 \mathrm{~cm}$.

Tujuan dari perawatan tali pusat adalah untuk mencegah infeksi dan miningkatkan pemisahan tali pusat dari perut. Dalam upaya untuk mencegah infeksi dan mempercepat pemisahan. Banyak zat yang berbeda dan kebiasaan-kebiasaan yang digunakan untuk perawatan tali pusat. Hanya dari beberapa penggunaannya yang telah dipelajari dengan baik zat-zat seperti triple dye, alkohol dan larutan chlorhexidine dianggap dapat mencegah terjadinya infeksi namun belum dapat bekerja dengan baik (Hasselquist, 2006).

Tali pusat sebaiknya dibiarkan lepas dengan sendirinya. Jangan memegang atau bahkan menariknya. Bila tali pusat belum juga puput setelah 4 minggu bisa menyebabkan tetanus neonatorum. Untuk mencegah terjadinya infeksi tetanus selain menjaga prinsip pencegahan infeksi, ibu juga harus mendapatkan suntik TT selama hamil (Wahyono, 2000).

Hasil penelitian ini sejalan dengan yang dilakukan oleh Tina Tulista (2011) di Puskesmas Plus Bara - Baraya Makassar menunjukan dari 115 responden dengan perawatan tehnik terbuka dengan penyembuhan luka tali pusat sebanyak 90 orang $(79,7 \%)$ dan yang tidak melakukan penyembuhan luka tali pusat sebanyak 25 orang $(20,3 \%)$. Dengan nilai $\mathrm{p}=0,175$ yang berarti tidak ada hubungan antara perawatan tehnik terbuka dengan penyembuhan luka tali pusat.

Diterbitkan oleh:

Universitas Wiralodra

Jln. Ir. H. Juanda Km 3 Indramayu, Jawa Barat 
Dari hasil penelitian yang penulis lakukan bahwa perawatan tehnik terbuka erat kaitannya dengan penyembuhan luka tali pusat. Hal ini dikarenakan pelaksanaan pada perawatan tehnik terbuka, setelah bayi selesai dimandikan dan kulit dikeringkan maka perawatan tali pusat sebagai berikut ; 1). Keringkan tali pusat mulai dari ujung sampai pangkal tali pusat dan daerah sekitarnya dengan diameter $2 \mathrm{~cm}, 2$ ). Biarkan tali pusat terbuka tanpa tutup/bungkus atau cukup dengan sehelai kassa steril saja, 3). Pakaian bayi dipakaikan, alat dirapikan kemudian tidurkan bayi dengan posisi sesuai kebutuhan. Pada makalah Pelatihan Managemen Asuhan Kebidanan yang diselenggarakan Pusat Perngembangan Keperawatan Carolus (2002) menyatakan jangan mengoleskan apapun ke tampuk tali pusat. Hindari pembungkusan tali pusat, tampuk tali pusat yamg tidak tertutup akan mengering dan puput lebih cepat dengan komplikasi yang sedikit. Sementara Cunningham (2007) menyatakan tali pusat mengering lebih cepat dan lepas lebih awal kalau terbuka dan karena itu pembalutan tidak dianjurkan.

Hasil penelitian efektifitas perawatan tehnik tertutup terhadap proses penyembuhan tali pusat pada bayi baru lahir di RSUD Labuang Baji tahun 2016, memperlihatkan $\rho$ value $0,235<0,05$ hal ini menunjukkan bahwa terdapat hubungan antara perawatan tehnik terutup dengan penyembuhan luka tali pusat. Hasil penelitian ini sejalan dengan yang dilakukan oleh wulan, D. (2012) di puskesmas Plus Bara Baraya Makassar menunjukkan dari 122 responden dengan perawatan tehnik tertutup terdapat ibu yang melakukan penyembuhan luka tali pusat sebanyak 90 orang $(78,4 \%)$ dan yang tidak melakukan penyembuhan luka tali pusat sebanyak 32 orang $(21,6 \%)$ dengan nilai $\mathrm{p}=0,214$ yang berarti tidak ada hubungan antara perawatan tehnik tertutup dengan penyembuhan luka tali pusat.

Perawatan tehnik tertutup adalah perawatan dengan menggunakan tutup kassa alkohol $70 \%$ pada tali pusat yang telah dilakukan perawatan. Yang menjadi pertimbangan dalam tehnik tertutup ini adalah ; 1). Pelindung luka tali pusat terhadap kontaminasi / infeksi berikutnya, 2). Melindungi luka tali pusat dari gesekan, 3). Membatasi gerakan kulit dan jaringan di bawahnya, 4). Menyerap sekret atau eksudat tetapi tidak boleh menghambat pengeluarannya dari luka (Sacharin, 2009). 
Dari hasil penelitian yang penulis lakukan bahwa perawatan tehnik tertutup erat kaitannya dengan penyembuhan luka tali pusat. Hal ini dikarenakan tali pusat sebaiknya dibiarkan lepas dengan sendirinya. Jangan memegang atau bahkan menariknya. Bila tali pusat belum juga puput setelah 4 minggu bisa menyebabkan tetanus neonatorum. Untuk mencegah terjadinya infeksi tetanus selain menjaga prinsip pencegahan infeksi, ibu juga harus mendapatkan suntik TT selama hamil (Wahyono, 2000). Pada penelitian menunjukkan bahwa tali pusat yang dibersihkan dengan air dan sabun cenderung lebih cepat puput (lepas) dari pada tali pusat yang debersihkan dengan alkohol.

\section{KESIMPULAN}

Berdasarkan hasil penelitian dan pembahasan disimpulkan bahwa : (1) Hasil penelitian menunjukkan bahwa tidak ada hubungan antara tehnik tertutup dengan penyembuhan luka tali pusat dimana nilai $\mathrm{p}=0,235$ lebih besar dari $\alpha=0,05$, ini berarti Ho diterima dan Ha ditolak. (2) Hasil penelitian menunjukkan bahwa tidak ada hubungan antara tehnik terbuka dengan penyembuhan luka tali pusat dimana nilai $\mathrm{p}=0,235$ lebih besar dari $\alpha=0,05$, ini berarti Ho diterima dan Ha ditolak.

\section{SARAN}

Diharapkan kepada pihak institusi pendidikan agar ada peningkatan keterampilan dalam memberikan pelajaran mengenai asuhan kebidanan khususnya mengenai penyembuhan luka tali pusat, diharapkan kepada pihak rumah sakit agar kiranya memberikan penyuluhan yang lebih kepada ibu mengenai penyembuhan luka tali pusat dengan tehnik tertutup dan terbuka dan diharapkan juga kepada peneliti selanjutnya untuk meneliti variabel yang lain serta menggunakan metode penelitian yang lain.

\section{UCAPAN TERIMAKASIH (Opsional)}

Peneliti mengucapkan terimakasih kepada RSUD Labuang Baji Makassar dan Jajarannya serta para ibu bersalin yang telah membantu peneliti demi kelancaran pelaksanaan penelitian ini. 


\section{DAFTAR PUSTAKA}

Amrullah S. 2015. Proses Penyembuhan Luka. http://dokumen.tips/documents/prosespenyembuhan-luka-fix.html - Diaksestanggal 14 Juni 2016

Aprillia Y. (2014). Wharton Jelly "Si Jelly Ajaib" dalam Tali pusat. http://www.bidankita.com/wharton-jelly-si-jelly-ajaib-dalam-tali-pusat/ - Diakses tanggal 14 juni 2016

Cunningham et al (2014). Obstetri Williams. Edisi 23. Jakarta: EGC, 1, PP: 63-436.

Dewi VN (2010). Asuhan Neonatus Bayi dan Anak Balita. Jakarta: Salemba Medika

Fatah, Syaiful. (2009). Perbedaan Lama Pelepasan Tali Pusat Antara Perawatan Tertutup dengan Dibiarkan Terbuka. Tesis FK Kedokteran UMY. Yogyakarta

Ganong, William F. (2002). Buku Ajar Fisiologi kedokteran. Jakarta: Ed.20. EGC.

Linda. (2006). Perawatan Tali Pusat Menggunakan ASI. Tesis Maternal dan Perinatal. UGM. Yogyakarta.

Neng, A.R. (2016). Hubungan Paritas dengan Perawatan Tali Pusat pada Bayi Baru Lahir oleh Ibu Postpartum di Klinik Bersalin $\mathrm{Hj}$. S. Tarigan di Kota Pangkalpinang. Jurnal Kesehatan, Vol 7, No 2, hlm.295-301.

Sodikin. (2009). Buku Saku Perawatan tali pusat. Jakarta: EGC.

Saryono. (2008). Metodologi Penelitian Kesehatan Penuntun Praktis Bagi Pemula. Yogyakarta: Mitra Cendikia Press Yogyakarta.

Sugiyono. 2007. Statistik untuk penelitian. Bandung: Alfabeta.

Utami, Deffi Gita Budhi. (2010). Perbedaan Lama Lepas Tali Pusat Perawatan Dengan Menggunakan Kassa Steril Dibandingkan Kasa Alkohol Di Desa Bowan Kecamatan Delanggu. Skripsi thesis UMS. Surakarta.

Pilliteri A. (2002). Buku Saku Perawatan Kesehatan Ibu Dan Anak. Jakarta: Penerbit EGC.

World Health Organization. Care Of Umbilical Cord; A Review Of The Evidence. WHO/RHT/MSM/98.4. 